\title{
Eczema among the Outdoor Diabetic Patients of Bangladesh Institute of Research and Rehabilitation in Diabetes, Endocrine and Metabolic Disorders (BIRDEM) Hospital, Dhaka
}

\author{
Mohammad Moniruzzaman Khan ${ }^{1}$, Mir Nazrul Islam ${ }^{2}$, Hamida Khanum ${ }^{3}$, Sohely Sultana ${ }^{4}$ \\ Received: May 21, 2015 Accepted: April 20, 2016 \\ doi: http://dx.doi.org/10.3329/jemc.v6i2.27764
}

\begin{abstract}
Background: Eczema is one of the important causes of public health problem. So, we conducted a study to assess the socio-demographic characteristics (age, sex, occupation, socio-economic condition, site of lesion, diabetes status etc) and to find out their relationship with the complicated eczema. Objective: The objective of the study was to find out the eczema cases attending in Department of Dermatology of Bangladesh Institute of Research and Rehabilitation in Diabetes, Endocrine and Metabolic Disorders (BIRDEM) Hospital and to identify the surface complications of eczema and the occurrence of eczema among the diabetic patients of BIRDEM Hospital. Materials and Methods: This cross-sectional study was carried out among the outdoor diabetic patients attending the Department of Dermatology of BIRDEM Hospital, Dhaka, Bangladesh during the period of $1^{\text {st }}$ September to $31^{\text {st }}$ November, 2014. Results: A total of 600 patients were interviewed. Of them, $60 \%$ were female and $40 \%$ were male. Among them, majority (29.17\%) were in the age group of 40-49 years. Most of the subjects (66.67\%) were service holders. Majority of the subjects (61.67\%) were from low socio-economic status. In majority cases (41.67\%) lesions were in hand and in $33.33 \%$ in legs. Diabetes was uncontrolled in $76.67 \%$ cases and only $15 \%$ controlled it and $8.33 \%$ controlled strictly. Conclusion: Factors like occupation, diabetes status etc. were found associated with high occurrence of eczema.
\end{abstract}

Key words: Eczema; Diabetes; Socio-economic status

J Enam Med Col 2016; 6(2): 93-96

\section{Introduction}

The skin is the largest organ of human body covering the entire surface which is subject to a wide range of medical conditions and infections ranging from simple manifestations to complicated ones. ${ }^{1}$ Skin is a potential source for invasive infections in neonates from developing countries such as Bangladesh where the level of environmental contamination is exceedingly high. $^{2}$

The relation between the skin and venereal diseases of the diabetic patients of different age groups and socio-

demographic characteristics is very complicated. ${ }^{3}$ The socio-demographic aspects are very important because different societies and social groups have different faiths to explain the causes of illness, the modes of treatment. ${ }^{4}$ Though it occurs in all classes but overcrowding, urbanization, industrialization, migration, excessive use of chemicals and cosmetics, environmental pollution, green house effect, delayed marriage and polygamy were found as factors for ignition and transmission of the disease. ${ }^{5}$

1. Registrar, Department of Dermatology, Bangladesh Institute of Research and Rehabilitation in Diabetes, Endocrine and Metabolic Disorders (BIRDEM) Hospital, Dhaka

2. Professor, Department of Dermatology, BIRDEM Hospital, Dhaka

3. Professor, Parasitology branch, Department of Zoology, University of Dhaka

4. Co-Researcher, Parasitology branch, Department of Zoology, University of Dhaka

Correspondence Mohammed Moniruzzaman Khan,Email: mmkrubel@yahoo.com 
A profile of skin diseases was done in children in Saurashtra in India, which revealed that the highest number of cases were of skin infections $(25 \%)$ followed by allergy $(8.5 \%)$ and miscellaneous $(8.25 \%)$ disorders. ${ }^{6}$

Eczema is a form of dermatitis or inflammation of the upper layer of the skin which is broadly applied to a range of persistent skin condition. ${ }^{7}$ Since eczema is the result of inflammation, all eczemas look alike. In a study done by Ahad et al all eczemas mostly resulted from contact with poison ivy, other contact dermatitis and atopic dermatitis. ${ }^{8}$ It is most common in infants and children. ${ }^{9}$

The people of Bangladesh suffer from eczema because of ignorance, illiteracy, poverty and apathy towards health problem. ${ }^{10}$ It is necessary to identify the risk factors in term of their age, sex, occupation, education, socio-economic condition, habit etc. As majority people suffers from eczema in their childhood, preventive measures should be taken in the early life. ${ }^{11}$ A study of skin disease pattern at the outpatient department of Dhaka Medical College Hospital was carried out in 1990, which revealed that out of 41,062 cases, $3.46 \%$ were eczema cases. ${ }^{12}$ Another study conducted on skin and sexually transmitted diseases at Enam Medical Collage Hospital (2009-10) revealed that in 12100 patients the percentage of eczema was $23.42 \%{ }^{13}$

Eczema is one of the most important skin diseases which cause the public health problem. ${ }^{14}$ Though it causes negligible mortality but most of the cases of eczema have chronic course and sufferings. ${ }^{15}$ Inadequate knowledge of the patients about skin diseases is another unfortunate situation to address this problem. In this perspective we designed this study to find out the eczema cases and to identify the surface complications of eczema and the occurrence of eczema among the diabetic patients attending the Department of Dermatology of Bangladesh Institute of Research and Rehabilitation in Diabetes, Endocrine and Metabolic Disorders (BIRDEM) Hospital, Dhaka.

\section{Materials and Methods}

This descriptive cross-sectional study was conducted among the diabetic patients in the department of Dermatology (Outpatient department) of Bangladesh Institute of Research and Rehabilitation in Diabetes, Endocrine and Metabolic Disorders (BIRDEM) Hospital. The period of the study was from September to November, 2014. The population of the study was the diabetic patients of all ages of different occupations. Among all the patients with skin disease only the eczema infected patients were selected. A total of 600 diabetic patients infected with eczema were selected purposively. A structured questionnaire was prepared at the beginning of the study. Before going to the actual study, the questionnaire was pretested. Then the final questionnaire was prepared.

Data collection procedure: Prior to data collection verbal consent was taken from the respondents. Data were collected through face to face interview by using the pretested questionnaire. The patients were examined by the professional doctor (dermatologist) and confirmed about the diagnosis of eczema before data collection. To build the support from the patients, the purpose of the study was explained to the patients. So the patients answered the questions to the best of their knowledge. Interview was conducted in a separate room for maintaining full confidentiality and each interview took about ten minutes.

Data processing and analysis: After completion of data collection, the obtained data were checked, verified and edited before tabulation. Data were copied in master compilation sheets and analyzed on the basis of the individual variable. Tables were made accordingly, narration of data was given and interpretation was done keeping in view the objectives of the study.

\section{Results}

Table I shows distribution of respondents according to age. Mean age of the subjects was 47.3 years. It was observed that, out of 600 patients, $70(11.66 \%)$ were aged between 20-29 years, $100(16.67 \%)$ were aged between 30-39 years, 175 (29.17\%) were aged between 40-49 years, 125 (20.83\%) were aged between 50-59 years, $85(14.17 \%)$ were aged between $60-69$ years, 45 (7.5\%) were aged between 70-79 years.

Out of 600 patients, $360(60 \%)$ were female and 240 $(40 \%)$ were male. It was seen that majority of the respondents $370(61.67 \%)$ were from lower class, 180 $(30 \%)$ were from middle class and $50(3.33 \%)$ were from upper class.

In the present study, $200(33.33 \%)$ were housewives and $400(66.67 \%)$ were service holders. It was also observed that majority (41.67\%) respondents had eczema in hand, $33.33 \%$ had it in legs and $18.33 \%$ in finger. Some other organs $(6.67 \%)$ were also affected. 
The study also revealed that out of 600 respondents majority (76.67\%) did not control diabetes, $8.33 \%$ controlled strictly and $15 \%$ just controlled it. It means that majority of eczema cases were in respondents with uncontrolled diabetes mellitus.

Table I: Distribution of respondents according to age

\begin{tabular}{|c|c|c|}
\hline Age (years) & Number & Percentage \\
\hline $20-29$ & 70 & 11.66 \\
\hline $30-39$ & 100 & 16.67 \\
\hline $40-49$ & 175 & 29.17 \\
\hline $50-59$ & 125 & 20.83 \\
\hline $60-69$ & 85 & 14.17 \\
\hline $70-79$ & 45 & 7.5 \\
\hline Total & 600 & 100 \\
\hline
\end{tabular}

Table II: Socio-demographic characteristics and other variables of the patients

\begin{tabular}{|l|l|r|r|}
\hline \multicolumn{1}{|c|}{ Variables } & \multicolumn{2}{|c|}{ Number } & Percentage \\
\hline \multirow{2}{*}{ Sex } & Male & 240 & 40 \\
\hline \multirow{2}{*}{ Socio- } & Female & 360 & 60 \\
\hline economic & Lower & 370 & 61.67 \\
\hline status & Middle & 180 & 30 \\
\hline \multirow{2}{*}{ Occupation } & Upper & 50 & 8.33 \\
\hline \multirow{3}{*}{ Site of lesion } & Service & 400 & 66.67 \\
& Housewife & 200 & 33.33 \\
& Hand & 250 & 41.67 \\
& Linger & 200 & 33.33 \\
& Others & 40 & 18.33 \\
\hline \multirow{2}{*}{ Diabetes } & Strictly controlled & 50 & 6.67 \\
\hline & Controlled & 90 & 8.33 \\
& Uncontrolled & 460 & 15 \\
\hline
\end{tabular}

Strictly controlled, HbA1c <7\%; Controlled, HbA1c 7-10\%; Uncontrolled, HbA1c $>10 \%$

\section{Discussion}

Eczema is one of the public health problems of mankind. It is found more or less in all ages and sexes and classes of the society and creates community health problems in the developing countries.
In the present study main variables were age, sex, occupation, educational status, knowledge about eczema, socio-economic conditions etc.

In the present study, the total number of the respondents was 600 . Out of 600 patients, $360(60 \%)$ were female and $240(40 \%)$ were male. Maximum patients affected with eczema were aged between 40-49 years. But a profile of skin diseases was done in children of Saurashtra in India ${ }^{6}$, which revealed $8.5 \%$ were eczema cases. Another study ${ }^{13}$ in Enam Medical College revealed $23.42 \%$ eczema cases among the patients attending Skin VD OPD. But in this study it was high in 40-49 years, probably due to the higher proportion of diabetic patients in that age group.

In the present study $200(33.33 \%)$ subjects were housewives and $400(66.67 \%)$ were service holders. A study conducted in Bangladesh on "Pattern of skin and VD disease in a Textile Mill" also supported this. ${ }^{15}$

It was also observed that majority $(41.67 \%)$ respondents suffered from eczema in hand. Then $33.33 \%$ had eczema in leg and $18.33 \%$ in finger. Some other organs $(6.67 \%)$ were also affected. This study is comparable with a study ${ }^{10}$ where eczema was more common on the leg $(26.4 \%)$ than on the hand $(20 \%)$.

In this study it was found that majority of the respondents $(370,61.67 \%)$ were from lower class, 180 $(30 \%)$ were from middle class and $50(3.33 \%)$ from upper class. So, the lower socio-economic persons were more affected by eczema. This is comparable with a study $^{14}$ where it was found that poor income group $(54.46 \%)$ was more affected with eczema and least from higher income group $(9.76 \%)$.

From this observation it can be said that eczema is a common disease in our country under certain prevailing conditions, such as lack of personal hygiene, undernutrition, low socio-economic condition etc. So it is important to take proper steps to address this problem.

\section{References}

1. The analyst-internet health report condition fungal skinnail. Available at: infection@htm.com. Accessed April 2014.

2. Darmstadt GL, Ahmed ASMNU, Saha SK, Chowdhury MAKA, Alam MA, Khatun M et al. Infection control practices reduce nosocomial infections and mortality in 
preterm infants in Bangladesh. Journal of Perinatology 2005; 25: 331-335. doi:10.1038/sj.jp.7211283.

3. Rahman MP. Skin diseases. Health and Medical J (The Independent), 2004: 6, 20.

4. Khanum H, Khanam P, Farhana R. Common skin diseases in relation to socio-demographic status among the outpatients in the department of skin and venereal disease of DMCH, Dhaka. Bangladesh J Zool 2007; 35(2): 391-396.

5. Khanum H, Alam S. The occurance of scabies among the outpatient children of Dhaka Medical College, Dhaka. Bangladesh J Zool 2010; 38(1): 7-11.

6. Anand IS, Gupta S. A profile of skin disorder in children in Saurashtra India. J of Indian Medical Association 1998; 96(8): 245-246.

7. Eczema is a skin condition in which areas of skin become red, rough and itchy. Available at: www.oxfordlearnersdictionaries.com. Accessed April 2014.

8. Ahad SMMA, Ali A, Maidul AZM. Disease pattern of patients attended in private chambers of dermatologist and venereologist and sex related disorders, Bangladesh J Dermatol Venerol Leprol 1994; 11(2): 34-36.
9. Atopic dermatitis, eczema and noninfectious immunodeficiency disorders. In: James WD, Berger TG, Elston DN (eds). Andrews' diseases of the skin: clinical dermatology. 10 ${ }^{\text {th }}$ edn. England: Saunders Elsevier, 2006: 69-90.

10. Ahmed S, Aftabuddin AKM. Common skin diseases. Bangladesh Med Res Counc Bull 1977; 11(1): 40-45.

11. Church RE, Knowledge J. Eczema in Sheffield, a family infestation. British Medical Journal 1978; No. 6115, Vol 1: 761-762.

12. Bhuia AL. A study of skin disease pattern at the outpatient department of Dhaka Medical College Hospital. J Dhaka Med Coll 1997; 1(1 and 2): 18-23.

13. Uddin MR, Sarwar KB, Akhter F, Baker A. Pattern of dermatological cases atteding Skin-VD Outpatient Department in a medical college of Bangladesh. J Enam Med Col 2011; 1(2): 67-70.

14. Al-Amin MA, Islam SMM, Haque MM. Morbidity pattern of dermatological causes. Bangladesh J Dermatol Venereal Leprol 1996; 14(1): 12-15.

15. Hossain MM. Pattern of skin and sexually transmitted disease in district hospital. Bangladesh J Dermatol Venerol Leprol 1993; 11(2): 7-9. 